\title{
Solubility and Activity of Oxygen in Liquid Germanium and Germanium-Copper Alloys
}

\author{
K. FITZNER, K. T. JACOB, AND C. B. ALCOCK
}

The solubility of oxygen in liquid germanium in the temperature range 1233 to $1397 \mathrm{~K}$, and in liquid germanium-copper alloys at $1373 \mathrm{~K}$, in equilibrium with $\mathrm{GeO}_{2}$ has been measured by the phase equilibration technique. The solubility of oxygen in pure germanium is given by the relation

$$
\log (\text { at. pct } 0)=-\frac{6470}{T}+4.24( \pm 0.07) \text {. }
$$

The standard free energy of solution of oxygen in liquid germanium is calculated from the saturation solubility, and recently measured values for the free energy of formation of $\mathrm{GeO}_{2}$, assuming that oxygen obeys Sievert's law up to the saturation limit. For the reaction,

$$
\begin{aligned}
& 1 / 2 \mathrm{O}_{2}(\mathrm{~g}) \rightarrow \underline{\mathrm{O}}_{\mathrm{Ge}} \\
& \begin{aligned}
\Delta \mathrm{G}^{\circ} & =-39,000+3.21 \mathrm{~T}( \pm 500) \mathrm{cal} \\
& =-163,200+13.43 T( \pm 2100) \mathrm{J} .
\end{aligned}
\end{aligned}
$$

where the standard state for dissolved oxygen is that which makes the value of activity equal to the concentration (in at. pct), in the limit, as concentration approaches zero. The effect of copper on the activity of oxygen dissolved in liquid germanium is found to be in good agreement with that predicted by a quasichemical model in which each oxygen was assumed to be bonded to four metal atoms and the nearest neighbor metal atoms to an oxygen atom are assumed to lose approximately half of their metallic bonds.

\begin{abstract}
P Revious studies ${ }^{1}$ on dilute solutions of oxygen were mainly confined to typical metallic systems in which there are fewer electrons than needed to form electron-pair bonds to all nearest neighbors. Investigation of the behavior of dissolved oxygen in group IVA elements like germanium, which is a covalently bonded and tetrahedrally coordinated semiconductor in the solid state, and of its alloy with group I B elements such as copper, in which the electron concentration changes rapidly with composition, is a natural extension of earlier studies. Recently Jacob and Alcock $^{2}$ have completed a similar study using an isopiestic technique on oxygen solubility in liquid galliumcopper alloys in which there is a well understood change in electron-atom ratio, and whilst the results indicate the predicted effects they do not cover the whole composition range. Furthermore information on liquid $\mathrm{Ge}-\mathrm{O}$ and $\mathrm{Cu}-\mathrm{Ge}-\mathrm{O}$ systems is useful from a practical as well as a theoretical point of view. A knowledge of the oxygen solubility in liquid germanium is important in the preparation of germanium based semiconductors grown from melts.

Recent models ${ }^{1,3}$ for the description of thermodynamic properties of oxygen in dilute solution in binary
\end{abstract}

K. FITZNER was on leave at the Department of Metallurgy and Materials Science, University of Toronto, when this investigation was undertaken. He has now returned to the Institute for Metals Research, Polish Academy of Sciences, 25 Reymonta St., 30-059 Krakow, Poland, K. T. JACOB is Senior Research Associate and Special Lecturer, Department of Metallurgy and Materials Science, University of Toronto, and C. B. ALCOCK is Professor, Department of Metallurgy and Materials Science, University of Toronto, Toronto, Canada M5S 1 A4.

Manuscript submitted August 31, 1976. alloys differ with respect to the significance of metalmetal interaction in the ternary solution. The equations developed by Jacob and Alcock ${ }^{1}$ for predicting the activity coefficient of oxygen at infinite dilution in binary alloys incorporate the activity coefficients of metallic components, whereas Wagner's equation ${ }^{3}$ does not contain terms representing the thermodynamic behavior of the metallic alloy. Because the heat of formation of liquid germanium-copper alloys shows a minimum at $X_{\mathrm{Ge}}=0.3$, introduction of the binary data in the model would result in a rapid change of the values for the activity coefficient of oxygen at this composition. Measurement of the variation of the activity coefficient of oxygen with composition of Ge$\mathrm{Cu}$ alloys is therefore useful for differentiating between the models.

The oxygen potential corresponding to the mixture of solid $\mathrm{Ge}$ and tetragonal $\mathrm{GeO}_{2}$ has been measured by Jacob, Alcock and Chan ${ }^{4}$ using a solid oxide galvanic cell in the temperature range 850 to $1150 \mathrm{~K}$. Navrot$\mathrm{sky}^{5}$ has measured the heat of transformation of tetragonal germanium dioxide into the high temperature hexagonal form. The free energy of formation of hexagonal $\mathrm{GeO}_{2}$ calculated from these results ${ }^{4,5}$ is in good agreement with that obtained from thermal data ${ }^{6 \rightarrow}$ The heats of fusion of hexagonal $\mathrm{GeO}_{2}$ (Ref. 5) and germanium metal ${ }^{9}$ are $3.84 \mathrm{kcal} /$ mole $(16.1 \mathrm{~kJ} /$ mole) and $8.83 \mathrm{kcal} /$ mole $(37 \mathrm{~kJ} / \mathrm{mole})$ respectively.

The equilibrium daigram of the system $\mathrm{Ge}-\mathrm{GeO}_{2}$ investigated by Trumbore, Thurmond and Kowalchik ${ }^{10}$ indicates that in the experimental temperature range used in the present study, 1233 to $1397 \mathrm{~K}$, liquid germanium is in equilibrium with the metal saturated liquid $\mathrm{GeO}_{2}$. (Stoichiometric $\mathrm{GeO}_{2}$ melts at $1390 \mathrm{~K}$.) 
The gas phase over the $\mathrm{Ge}+\mathrm{GeO}_{2}$ mixture contains the $\mathrm{O}_{2}, \mathrm{Ge}$ and $\mathrm{GeO}$ species of which the latter predominates. ${ }^{11}$ A conventional two-phase equilibrium technique was used in the work reported here to obtain the saturation solubility of oxygen in liquid germanium and germanium-copper alloys. The fact that germanium crystallizes in the diamond structure meant that metal samples free from oxide surface contamination could readily be obtained by cleavage of the surface layers of the metal.

\section{EXPERIMENTAL METHOD}

\section{Materials}

The germanium metal and the germanium dioxide powder used in this study were 99.999 pet pure and were obtained from CERAC Inc. Copper metal was obtained from Cominco and was 99.99 pct pure.

\section{Apparatus}

The experimental method is similar to that described previously. ${ }^{2}$ However, it was necessary to prevent contact of the silica capsule with $\mathrm{GeO}_{2}$, because the high temperature hexagonal form of $\mathrm{GeO}_{2}$ is isostructural with $\beta$-quartz and the two oxides may be expected to be completely miscible. Figure 1 shows the scheme of the experimental arrangement. Germanium metal (or alloy) was contained in a $\mathrm{GeO}_{2}-$ lined alumina crucible closed with an alumina lid. The alumina crucible was then placed inside a closed-end silica tube and sealed under vacuum. Almost perfect self-sealing of the alumina crucible with the lid was observed in the presence of $\mathrm{GeO}_{2}$. This was probably facilitated by a small temperature gradient $0.5 \mathrm{~K}$ $\mathrm{cm}^{-1}$ ) along the alumina crucible resulting in some

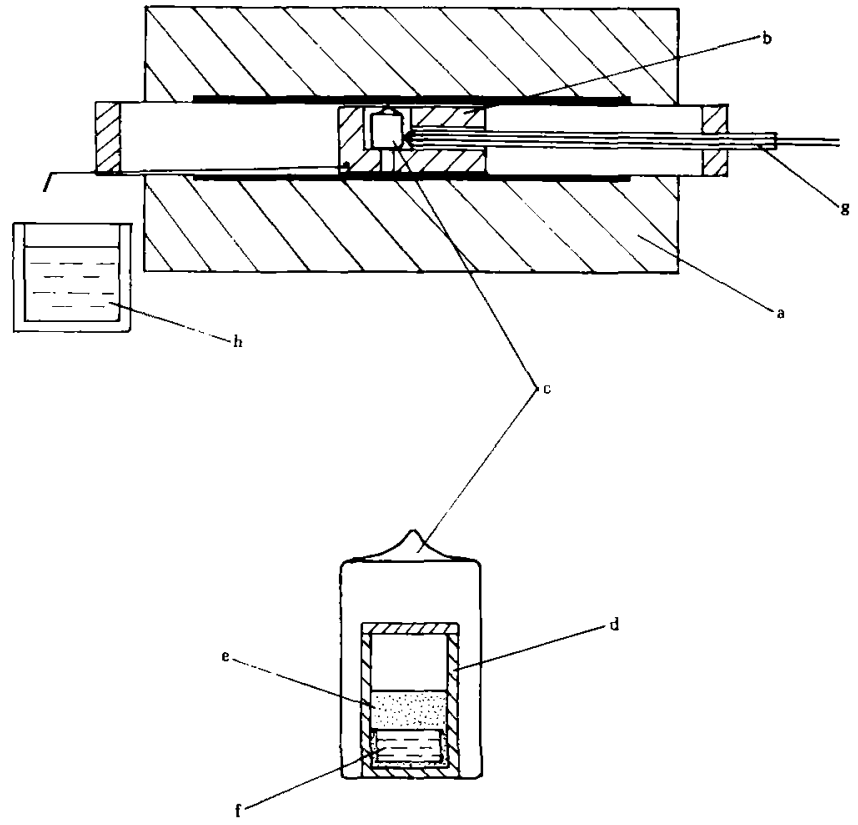

Fig. 1-Apparatus for solubility measurements: $(a)$ resistance furnace with a uniform temperature zone, $(b)$ brick, (c) silica capsule, $(d)$ alumina crucible, $(e)$ germanium dioxide, $(f)$ germanium or germanium-copper alloy, $(g)$ thermocouple, $(h)$ liquid nitrogen quench.
Table I. Oxygen Solubility in Pure Liquid Germanium

\begin{tabular}{cc}
\hline Temperature, $K$ & Oxygen, At. Pct \\
\hline 1397 & 0.392 \\
1370 & 0.344 \\
1351 & 0.277 \\
1343 & 0.250 \\
1317 & 0.209 \\
1287 & 0.178 \\
1276 & 0.129 \\
1248 & 0.107 \\
1242 & 0.109 \\
1228 & 0.061 \\
1222 & 0.115 \\
\hline
\end{tabular}

condensation of GeO near the lid. Some GeO molecules escaped from the alumina crucible before a good seal between the crucible and the lid was achieved, and these molecules reacted with the silica capsule to produce a solid solution of $\mathrm{GeO}_{2}$ in $\mathrm{SiO}_{2}$ and a fine deposit of metallic germanium. The extent of the reaction as judged from the discoloration of the silica tube was small. Examination of the alumina crucibles at the end of the experiments indicated that at the interface between the $\mathrm{GeO}_{2}$ layer and the alumina crucible there was a thin layer of the compound $3 \mathrm{Al}_{2} \mathrm{O}_{3} \cdot 2 \mathrm{GeO}_{2},{ }^{12}$ " germanium mullite". The germanium metal sample was only in contact with the large excess of $\mathrm{GeO}_{2}$ which was present and hence the formation of the ternary oxide which occurred should not have affected the equilibrium distribution of oxygen between the metal and $\mathrm{GeO}_{2}$. There were indications from visual and microscopic examination that the $\mathrm{GeO}_{2}$ oxide-layer in immediate contact with the metal was in fact a liquid phase during the experiment. The thickness of the liquid oxide film around the metal bead was approximately $0.2 \mathrm{~mm}$. This liquid appeared to have existed only at the interface between the metal and solid $\mathrm{GeO}_{2}$; it did not contact either germanium mullite or alumina. After keeping the system at constant temperature for $24 \mathrm{~h}$, the capsule was quenched either in water or in liquid nitrogen. It was found that, because of the large thermal mass of the alumina crucible and silica capsule, quenching in water was not always sufficiently rapid to prevent the loss of oxygen as GeO gas from the sample.

\section{Analysis}

After quenching, the capsule was broken and the oxide layer was removed from the metal surface by cleavage. Oxygen analysis of the metal (or alloy) was done using the "LECO RO-16 Oxygen Analyzer", as discussed in an earlier paper.

\section{RESULTS}

The saturation solubility of oxygen in liquid germanium obtained by analysis of the metal after isothermal equilibration with its oxide is plotted as a function of the reciprocal of the absolute temperature in Fig. 2. The results of analysis at corresponding temperatures are shown in Table $I$. The least-mean square line through the experimental points may be 
represented by the equation

$$
\log (\text { at. pet } 0)=-\frac{6470}{T}+4.24( \pm 0.07) \text {. }
$$

The solution of $\mathrm{GeO}_{2}$ in liquid germanium may be expressed by the reaction

$$
1 / 2 \mathrm{GeO}_{2}(1) \rightarrow 1 / 2 \mathrm{Ge}(1)+\underline{\mathrm{O}} \mathrm{Ge}
$$

where the standard state for oxygen is chosen such that its activity is equal to atom percent in an infinitely dilute solution. The free energy change for the Reaction [2] has been calculated from the relation

$$
\begin{aligned}
\Delta G_{2}^{0} & =-R T \ln K=-4.575 T \log \frac{\text { at. pct } 0}{\alpha_{\mathrm{GeO}_{2}}^{1 / 2}} \mathrm{cal} \\
& =29,600-19.54 T( \pm 400) \mathrm{cal} \\
& =124,000-81.7 T( \pm 1700) \mathrm{J} .
\end{aligned}
$$

Since the solubility of oxygen in liquid germanium is between 0.1 and 0.4 at. pct in the range of temperatures covered in this study, the activity of germanium may be taken as equal to unity. However, the activity of $\mathrm{GeO}_{2}$ (Ref. 1) cannot be taken to be unity. Calculations based on the phase diagram for the system Ge $+\mathrm{GeO}_{2}$ (Ref. 10) and calorimetric values for the heat of fusion of tetragonal and hexagonal $\mathrm{GeO}_{2}$ (Ref. 5) suggest that the activity of $\mathrm{GeO}_{2}$ exhibits negative deviations from Raoult's law, which is rather unusual in a system with a miscibility gap. We have therefore preferred to assume that the activity of $\mathrm{GeO}_{2}$ in the liquid oxide phase containing dissolved germanium is Raoultian. The mean value of $a_{\mathrm{GeO}}$ chosen in the range of temperatures 1223 to $1373 \mathrm{~K}$ is equal to 0.86 . The maximum error introduced by this assumption on the free energy of solution of molecular oxygen in liquid germanium is $400 \mathrm{cal}( \pm 1700 \mathrm{~J})$. When the activity of $\mathrm{GeO}_{2}$ in the liquid oxide obeys Raoult's law, the activity of germanium in the melt must obey Henry's law. The mole fraction of $\mathrm{GeO}_{2}$ in the liquid oxide has a value which depends on the activity of germanium in the alloy in equilibrium with the liquid oxide $\left(X_{\mathrm{GeO}_{2}}=1-0.14 a_{\mathrm{Ge}}\right)$.

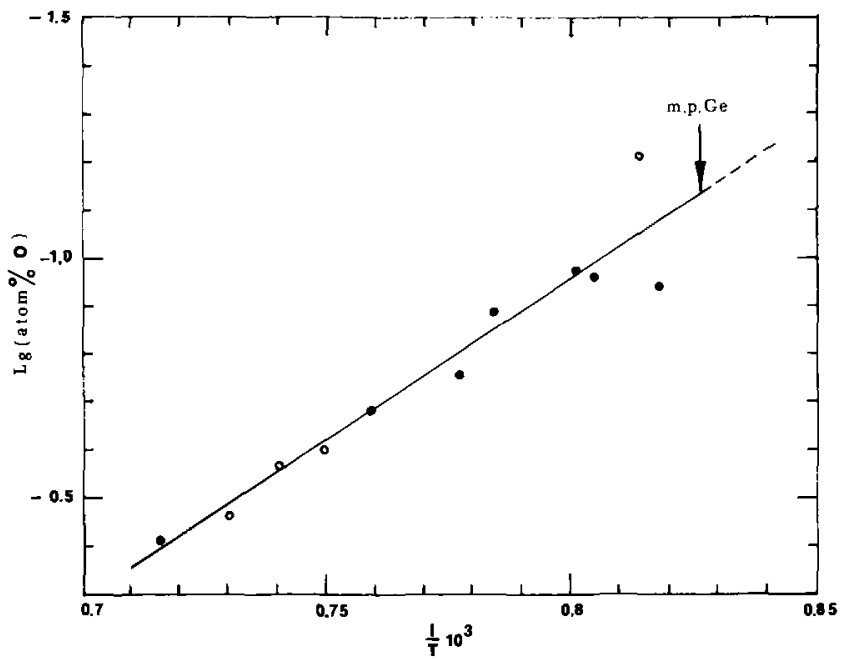

Fig. 2-Temperature dependence of oxygen solubility in liquid germanium; --quenched in liquid nitrogen; $\circ$-quenched in water.

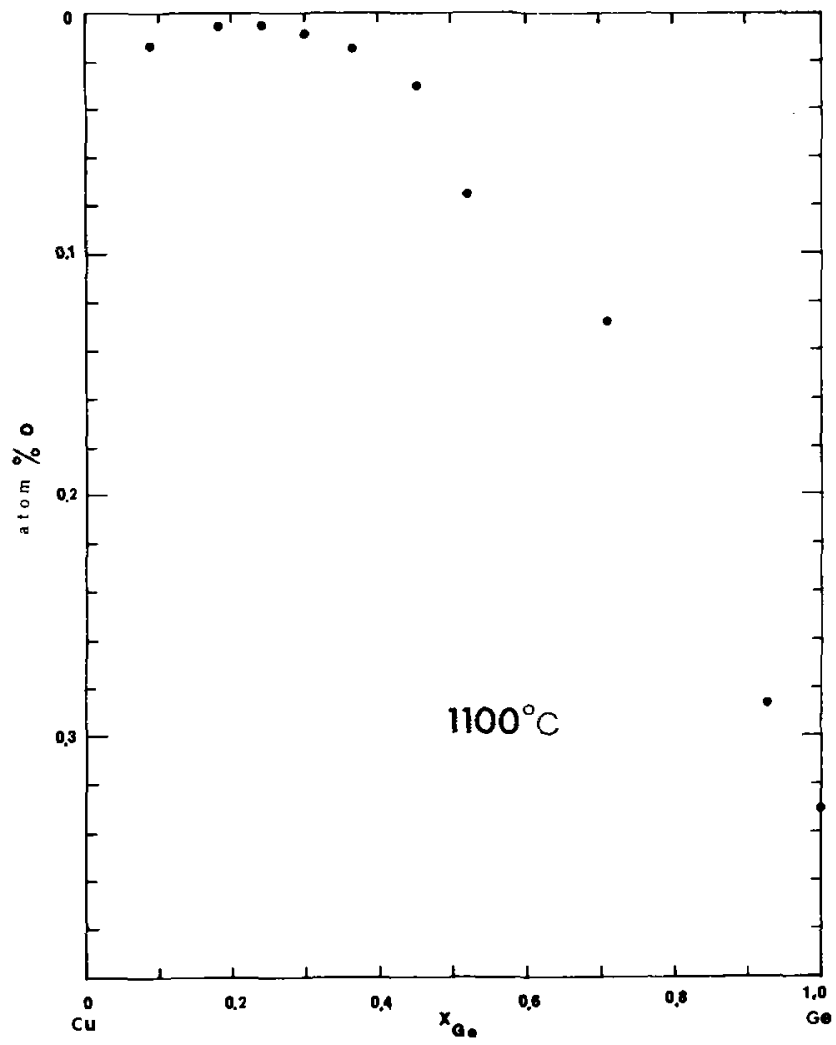

Fig. 3-Oxygen solubility in liquid copper-germanium alloy at $1373 \mathrm{~K}$.

When Eq. [3] is combined with the standard free energy of formation for the reaction

$$
1 / 2 \mathrm{Ge}(1)+1 / 2 \mathrm{O}_{2}(\mathrm{~g}) \rightarrow 1 / 2 \mathrm{GeO}_{2}(1)
$$

calculated from Refs. 4,5 and 9

$$
\begin{aligned}
\Delta G^{0} & =-68,600+22.75 T( \pm 250) \mathrm{cal} \\
& =-287,100+95.2 T( \pm 1000) \mathrm{J}
\end{aligned}
$$

one obtains the standard free energy of solution of molecular oxygen in liquid germanium, assuming Sievert's law is obeyed by oxygen:

$$
\begin{aligned}
1 / 2 \mathrm{O}_{2}(\mathrm{~g}) \rightarrow \underline{\mathrm{O}}_{\mathrm{Ge}} & \\
\Delta G^{0} & =-39,000+3.21 T( \pm 500) \mathrm{cal} \\
& =-163,200+13.43 \mathrm{~T}( \pm 2100) \mathrm{J} .
\end{aligned}
$$

The variation of the saturation solubility of oxygen in liquid copper-germanium alloys at $1373 \mathrm{~K}$ as a function of the alloy composition is shown in Fig. 3; the results of analysis are also summarized in Table II. The alloy composition was calculated from the weights of the component metals after the application of a small correction for loss of Ge as GeO to the gas phase. The correction was based on the small observed change in weight of the alloy during the experiments. Chemical analysis of the copper-germanium alloy samples showed that the difference between the compositions which were calculated in this way and the analyzed alloy compositions was not more than 0.01 mole fraction of $\mathrm{Ge}$. The solubility of oxygen decreases with the addition of copper up to 80 at. pct. At higher copper concentration, the solubility of oxygen increases and it can be calculated that at 1 at. pct germanium the 
Table II. Oxygen Solubility in Liquid Copper-Germanium Alloy at $1373 \mathrm{~K}$

\begin{tabular}{cc}
$X_{\mathrm{Cu}}$ & Oxygen, At. Pct \\
\hline 0.08 & 0.287 \\
0.29 & 0.129 \\
0.48 & 0.077 \\
0.55 & 0.030 \\
0.64 & 0.015 \\
0.70 & 0.0086 \\
0.76 & 0.0046 \\
0.82 & 0.0049 \\
0.91 & 0.0137 \\
\hline
\end{tabular}

solubility of oxygen is equal to approximately 1 at. pct. There is only one stable compound $\mathrm{CuGeO}_{3}$ in the system $\mathrm{Cu}_{2} \mathrm{O}-\mathrm{CuO}-\mathrm{GeO}_{2}$ (Ref. 13) and the dissociation pressure of $\mathrm{CuGeO}_{3}$ at $1273 \mathrm{~K}$ according to the reaction

$$
\mathrm{CuGeO}_{3}(\mathrm{~s}) \rightarrow 1 / 2 \mathrm{Cu}_{2} \mathrm{O}(\mathrm{s})+\mathrm{GeO}_{2}(\mathrm{~s})+1 / 4 \mathrm{O}_{2}(\mathrm{~g})
$$

is $2.22 \times 10^{-4}$ atm. ${ }^{14}$ The oxygen pressure over a $\mathrm{Cu}-\mathrm{Ge}$ alloy containing 1 at. pet $\mathrm{Ge}$ in equilibrium with $\mathrm{GeO}_{2}$ is $1.7 \times 10^{-8}$ atm, so that the oxide phase for alloy compositions covered in this study is $\mathrm{GeO}_{2}$. According to Speranskaya ${ }^{13}$ the phase diagram for the system $\mathrm{Cu}_{2} \mathrm{O}-\mathrm{GeO}_{2}$ is of the eutectic type and a liquid phase is stable at $1373 \mathrm{~K}$ for $0.95>X_{\mathrm{GeO}_{2}}>0.25$. For copper-rich alloys some displacement reaction of the type

$$
\mathrm{GeO}_{2}(1)+4 \mathrm{Cu}(1) \rightarrow 2 \mathrm{Cu}_{2} \mathrm{O}(1)+\mathrm{Ge}(1)
$$

can be anticipated. Calculations based on the thermodynamic data on liquid $\mathrm{Cu}-\mathrm{Ge}$ alloys and liquid $\mathrm{Cu}_{2} \mathrm{O}$ and $\mathrm{GeO}_{2}$, and activities in $\mathrm{Cu}_{2} \mathrm{O}-\mathrm{GeO}_{2}$ system estimated from the phase diagram ${ }^{13}$ suggest that for an alloy containing 9 at. pct germanium the liquid phase contains less than 4 mole pct $\mathrm{Cu}_{2} \mathrm{O}$.

From the results of this study, the Sievert's law constant $(S)$ for oxygen in germanium-copper alloy has been calculated using the relation

$$
\frac{1}{S_{O(\mathrm{Ge}+\mathrm{Cu})}}=\frac{{ }^{1 / 2} \mathrm{O}_{2}}{\text { at. pct } 0}=\frac{K a_{\mathrm{GeO}_{2}}}{a_{\mathrm{Ge}}} \cdot \frac{1}{(\text { at. } \operatorname{pct} 0)}
$$

where $K$ is an equilibrium constant of the reaction

$$
\mathrm{GeO}_{2}(1) \rightarrow \mathrm{Ge}(1)+\mathrm{O}_{2}(\mathrm{~g})
$$

As $\mathrm{X}$-ray examination of the oxide phase in equilibrium with the alloy showed the absence of copper oxide, and thermodynamic calculations indicate the presence of less than 4 mole pct $\mathrm{Cu}_{2} \mathrm{O}$ for the alloy containing the lowest concentration of germanium, the activity of $\mathrm{GeO}_{2}$ was taken as the mole fraction of $\mathrm{GeO}_{2}$ in the melt in equilibrium with the alloy phase, in which the germanium activity is known. Activities in the alloys at $1373 \mathrm{~K}$ were obtained from the calorimetric measurements of the heat of mixing reported by Predel and Stein, ${ }^{15}$ Itagaki and Yazawa ${ }^{16}$ and Takeuchi et al, ${ }^{17}$ and activities of $\mathrm{Cu}$ and $\mathrm{Ge}$ determined at $1573 \mathrm{~K}$ from mass-spectrometric study by Alcock et al..$^{18}$ Activities in binary $\mathrm{Cu}-\mathrm{Ge}$ system at $1373 \mathrm{~K}$, relative to pure metals as standard states, are summarized in Table III. The standard free energy of solution of molecular oxygen in liquid copper $\left(1 / 2 \mathrm{O}_{2} \rightarrow \underline{0} \mathrm{Cu}\right)$ is given by Ref. 19

$$
\begin{aligned}
\Delta G^{0} & =-20,540+1.72 T( \pm 150) \mathrm{cal} \\
& =-85,950+7.21 T( \pm 600) \mathrm{J}
\end{aligned}
$$

where the standard state for dissolved oxygen is chosen such that in an infinitely dilute solution its activity is equal to its atom pct. The ratio of the activity coefficient of oxygen in liquid germanium to that in liquid copper which is given by $\gamma_{O}(\mathrm{Ge}) / \gamma_{O}(\mathrm{Cu})$ $=S_{O(\mathrm{Cu})} / S_{O(\mathrm{Ge})}$ is therefore $1 / 412(i . e ., \log \gamma O(\mathrm{Ge})$ $\left.-\log \gamma_{O}(\mathrm{Cu})=-2.61\right)$. The variation of the oxygen activity coefficient with alloy composition at $1373 \mathrm{~K}$ relative to oxygen in liquid copper is shown in Fig. 4.

\section{DISCUSSION}

The experimental values for the activity coefficient of oxygen in liquid $\mathrm{Cu}-\mathrm{Ge}$ alloy at $1373 \mathrm{~K}$ are compared in Fig. 4 with those calculated from a quasichemical model suggested by Jacob and Alcock. ${ }^{1}$ According to that model, each oxygen atom makes $n$ bonds with metal atoms and the electronic configuration around the metal atoms bonded to oxygen is altered so that the strength of metal-metal bonds made by these atoms is reduced by a factor of $(1-\alpha)$. Under these assumptions, the activity coefficient of oxygen can be predicted:

$$
\frac{1}{\gamma_{O(\mathrm{Cu}+\mathrm{Ge})}^{1 / n}}=X_{\mathrm{Ge}} \frac{\gamma_{\mathrm{Ge}(\mathrm{Cu}+\mathrm{Ge})}^{\alpha}}{\gamma_{O(\mathrm{Ge})}^{1 / n}}+X_{\mathrm{Cu}} \frac{\gamma_{\mathrm{Cu}(\mathrm{Cu}+\mathrm{Ge})}^{\alpha}}{\gamma_{O(\mathrm{Cu})}^{1 / n}}
$$

where $X_{\mathrm{Ge}}$ and $X_{\mathrm{Cu}}$ are mole fractions of germanium and copper in the solution, $\gamma_{O}(\mathrm{Ge}), \gamma_{O}(\mathrm{Cu})$ and $\gamma O(\mathrm{Cu}+\mathrm{Ge})$ are activity coefficients of oxygen in pure germanium, copper and the alloy respectively, $\gamma_{\mathrm{Ge}(\mathrm{Cu}+\mathrm{Ge})}$ and $\gamma_{\mathrm{Cu}(\mathrm{Cu}+\mathrm{Ge})}$ are activity coefficients of the alloy components. It has been shown ${ }^{1}$ that for a large number of systems the experimental data can be reconciled with the model for values $n=4$ and $\alpha=1 / 2$. A value of $n=4$ is compatible with tetrahedral interstitial occupancy by oxygen atoms, and with the high values for diffusivity of oxygen in solid metals. ${ }^{20-23}$ Analysis of the geometry of liquids in terms of the random close packed hard sphere model by Bernal and coworkers ${ }^{24}$ indicate that 73 pct of the holes in the liquid are tetrahedral and 20 pct are half

Table III. Evaluated Activities and Activity Coefficients in Copper-Germanium System at $1373 \mathrm{~K}$

\begin{tabular}{lllll}
\hline$X_{\mathrm{Ge}}$ & $\gamma_{\mathrm{Ge}}$ & $a_{\mathrm{Ge}}$ & $\gamma_{\mathrm{Cu}}$ & $a_{\mathrm{Cu}}$ \\
\hline 0.1 & 0.0478 & 0.005 & 0.909 & 0.82 \\
0.2 & 0.153 & 0.03 & 0.703 & 0.56 \\
0.3 & 0.429 & 0.13 & 0.456 & 0.32 \\
0.4 & 0.806 & 0.32 & 0.249 & 0.15 \\
0.5 & 0.993 & 0.50 & 0.218 & 0.11 \\
0.6 & 1.018 & 0.61 & 0.211 & 0.08 \\
0.7 & 1.007 & 0.70 & 0.215 & 0.07 \\
0.8 & 1.002 & 0.80 & 0.218 & 0.04 \\
0.9 & 0.999 & 0.90 & 0.220 & 0.02 \\
\hline
\end{tabular}




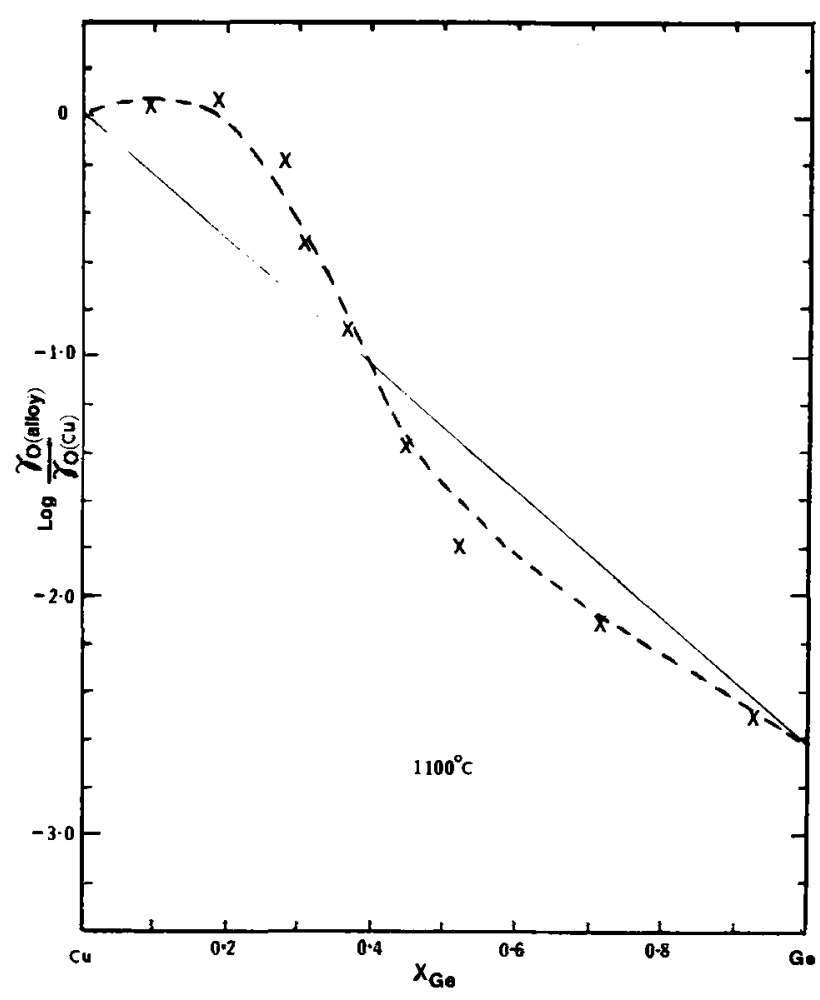

Fig. 4-Composition dependence of the activity coefficient of oxygen in liquid copper-germanium alloys at $1373 \mathrm{~K}$, relative to oxygen in pure copper; X-experimental results; - - - Quasichemical model of Jacob and Alcock, $n=4$ and $\alpha=1 / 2$.

octahedral. Moreover, because of the strong interaction between the metal and dissolved oxygen atoms, and the current lack of information on the nature of this bond, useful estimates of the coordination number of oxygen cannot be made from consideration of radius ratios. An explanation for the applicability of the quasichemical Eq. [1] may reside in the covalent to metallic transition in germz nium on melting, which has been demonstrated by conductivity measurements. ${ }^{25}$ Van Vechten ${ }^{26}$ has shown that the large entropy of fusion of germanium can be accounted for by a bonding contribution ( $4 \mathrm{R} \ln 2$ ) in addition to the nor mal entropy of fusion of metals which arises from vibrational changes. Springfellow and Greene ${ }^{27}$ have applied a quasichemical model for predicting phase diagrams of systems composed of elements III and V of the periodic table, using a value of six for the coordination number in the liquid state. An X-ray diffraction study of liquid germanium ${ }^{28}$ suggests that each atom has 7.1 nearest neighbors and its structure is similar to that of the high pressure modification in the solid state. The interference function of liquid germanium cannot be fitted to one derived from a random collection of hard spheres, but is compatible with a 'ball and spoke' model based on a white tin-like short range order.

The experimental results indicate a sharp change in the activity coefficient of oxygen at $X_{\mathrm{Ge}}=0.33$. $X$-ray diffraction investigations by Isherwood and Orton ${ }^{29,30}$ on liquid germanium-copper alloys using the partial interference function method suggest that an alloy containing $\sim 36$ at. pct germanium has the highest average coordination number (or largest area under the first peak in the radial distribution function). Lazarev $e t a l^{31}$ have shown that the maximum deviation of measured surface tension of liquid germanium-copper alloys from the ideal one occurs at $X_{\mathrm{Ge}} \cong 0.35$. Electrical resistivity measurements of Guntherodt and Tieche $^{32}$ also suggest changes in the structure of the liquid alloy about that composition. Since Wagner's model $^{3}$ neglects interactions between copper and germanium atoms, it cannot account for the significant change in the slope of the logarithm of the activity coefficient of oxygen $v$ s mole fraction at $X_{\mathrm{Ge}}=0.35$ (Fig. 4). The Wagner model is based on the parabolic dependence of the solvation energy on the number of copper and germanium atoms in the solvation shell of oxygen atoms, which are assumed to be located at quasiinterstitial sites in the liquid.

The heat and entropy values for oxygen dissolution in liquid germanium are compared in Fig. 5 with those obtained for silver, ${ }^{33,34}$ copper, ${ }^{35}$ lead, ${ }^{35,36}$ tin, ${ }^{37,38}$ gallium, ${ }^{2}$ sodium, ${ }^{39,40}$ and lithium. ${ }^{41,42}$ For metals with full $d$-shell, there appears to be a rough correlation between the heat and entropy of solution of oxygen. The decrease in the partial entropy of oxygen with increasing strength of the metal-oxygen bond suggests that the correlation is the result of vibrational effects. This recalls Kubaschewski's earlier observation ${ }^{42}$ that the maximum values for the integral heat and excess entropy for a large number of binary alloys obey an approximately linear relation. Since the heats of $\mathrm{mix}-$ ing of most binary alloys are significantly smaller than the heats of solution of oxygen, any departure from a linear correlation would be difficult to distinguish, given the range of experimental uncertainties for the heat and entropy terms in binary alloys. Another interesting feature of Fig. 5 is the observation that the partial entropy of oxygen in liquid transition metals, $\mathrm{Fe}, \mathrm{Ni}$, Co (Refs. 43 to 45 ) and uranium ${ }^{41,46}$ with unfilled $d$-shells, appears to be significantly different. Because of the experimental errors and the narrow temperature range covered in the free energy measurements, there are large uncertainties in the partial entropies of oxygen in these metals, but the trend to a higher entropy value would suggest a bonding contribution.

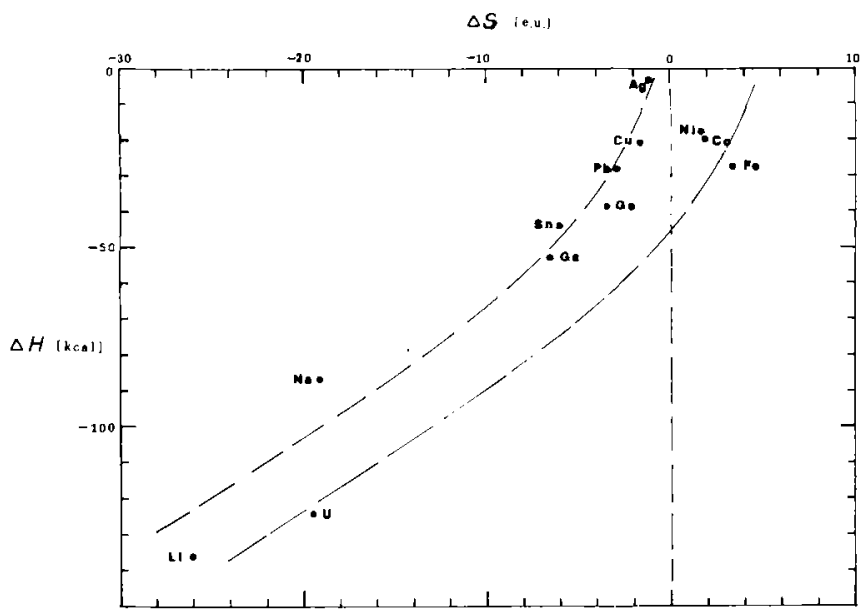

Fig. 5-Correlation between heat and entropy of solution of molecular oxygen in liquid metals; $1 / 20_{2} \rightarrow \mathrm{O}_{\mathrm{M}}$. The standard state for dissolved oxygen is chosen such that its activity is equal to its atom pact at infinite dilution. 


\section{ACKNOWLEDGMENTS}

The authors are grateful to the National Research Council of Canada for financial support and to $\mathrm{Mr}$. Chung Kook Kim for performing oxygen analyses.

\section{REFERENCES}

1. K. T. Jacob and C. B. Alcock: Acta Met., 1972, vol. 20, p. 221.

2. K. T. Jacob and C. B. Alcock: J. Less-Common Metals, 1977, vol. 53, p. 211. 3. C. Wagner: Acta Met., 1973, vol. 21, p. 1927.

4. K. T. Jacob, C. B. Alcock, and J. C. Chan: Acta Met., 1974, vol. 22, p. 545.

5. A. Navrotsky: J. Inorg. Nucl. Chem., 1971, vol. 33, p. 1119.

6. P. Gross, C. Hayman, and J. F. Bingham: Trans. Faraday Soc., 1966, vol. 62, p. 2388 .

7. E. G. King: J. Amer. Chem. Soc., 1958, vol. 80, p. 1799.

8. K. K. Kelley and A. J. Christensen: U.S. Bur. Mines, 1961, Rep. Invest. 5710, 1.

9. R. Hultgren, P. D. Desai, D. T. Hawkins, M. Gleiser, K. K. Kelley, and D. D. Wagman: Selected Values of the Thermodynamic Properties of the Elements, Am. Soc. Metals, Ohio, 1973.

10. F. A. Trumbore, C. D. Thurmond, and M. Kowalchik: J. Chem. Phys, 1956, vol. 24 , p. 1112

11. J. Drowart, F. Degreve, G. Verhaegen, and R. Colin: Trans. Faraday Soc., 1965 , vol. 61 , p. 1072

12. J. L. Miller, R. McCormick, and G. Ampian: J. Amer. Chem. Soc., 1967, vol. 50, p. 69.

13. E. I. Speranskaya: Izv. Akad. Nauk S.S.S.R., Neorg. Mater., 1967, vol. 3, p. 1458.

14. A. Navrotsky: J. Solid State Chem., 1974, vol. 11, p. 10.

15. B. Predel and D. W. Stein: Zeit. Naturforschung, 1971, vol. 26 a, p. 722.

16. K. Itagaki and A. Yazawa: J. Jap. Inst. Metals, 1971, vol. 35, p. 383.

17. S. Takeuchi, O. Uemura, and S. Ikeda: Prop. Liquid Metals, Proc. Inst. Conf. 2nd, London, 1972.

18. C. B Alcock, R. Sridhar, and R. C. Svedberg: J. Chem. Thermodynamics, 1970, vol. 2, p. 255.

19. K. T. Jacob and J. H. E. Jeffes: Trans. Inst. Mining Met, 1971, vol. 80, p. C32
20.W. Eichenauer and G. Muller: Z. Metalk., 1962, vol. 53, p. 321.

21. H. Rickert and R. Steiner: Z. Phys. Chem., 1966, vol. 49, p. 127

22. R. L. Pastorek and R. A. Rapp: Trans. TMS-AIME, 1969, vol. 245, p. 171 I.

23. J. H. Swisher and E. T. Turkdogan: Trans. TMS-AIME, 1967, vol. 239, p. 429

24. J. D. Bernal: Liquids: Structure, Properties and Solid Interactions, T. J. Hughel, ed., Elsevier, New York, 1965.

25. V. M. Glazov, S. V. Chizhevskaya, and N. N. Glagoleva: Liquid Semiconductors, Plenum Press, New York, 1969.

26. I. A. Van Vechten: Phys. Rev., 1973, vol. 7B, p. 1479.

27. G. B. Springfellow and P. E. Greene: J. Phys. Chem. Solids, 1969, vol. 30, p. 1779.

28. S. P. Isherwood, B. R. Orton, and A. Manaila: J. Non-Cryst. Solids, 1972 vols. $8-10$, p. 691

29. S. P. Isherwood and B. R. Orton: Phys. Letters, 1970, vol. 31 a, p. 164

30. S. P. Isherwood and B. R. Orton: J. Phys. C, Solid State Phys., 1972, vol. 5, p. 2977.

31. V. B. Lazarev, V. S. Arakelyan, and A. V. Pershikov: Russ. J. Phys. Chem., 1968 , vol. 42 , p. 147.

32. H. J. Guntherodt and Y. Tieche: Helv. Phys. Acta, 1968, vol. 41, p. 855.

33. C. Diaz, C. R. Mason, and F. D. Richardson: Trans. Inst. Mining Met, 1966, vol. 75 , p. C183.

34. E. H. Baker and M. I. Talukdar: Trans. Inst. Mining Met., 1968, vol. 77, p. C128.

35. K. T. Jacob and J. H. E. Jeffes: Trans. Inst. Mining Met., 1971, vol. 80, p. C32.

36. C. B. Alcock and T. N. Belford: Trans. Faraday Soc., 1964, vol. 60, p. 822

37. C. B. Alcock and T. N. Belford: Trans. Faraday Soc., 1965, vol. 61, p. 442.

38. K. T. Jacob, S. K. Seshadri, and F. D. Richardson: Trans. Inst. Mining Met., 1970 , vol. 79 , p. C274.

39. C. B. Alcock and G. P. Stavropoulos: Can. Met. Quart., 1971, vol. 10, p. 257. 40. JANAF Thermochemical Tables, 2nd edition, NSRDS-NBS 37.

41. R. P. Elliott: Constitution of Binary Alloys, McGraw Hill, New York, 1965.

42. O. Kubaschewski, E. L. Evans, and C. B. Alcock: Metallurgical Thermochemistry, 4th edition, Pergamon Press, 1967

43. T. P. Floridis and J. Chipman: Trans. TMS-AIME, 1958, vol. 212, p. 549

44. J. E. Bowers: J. Inst. Metals, 1961.62, vol. 90, p. 321.

45. K. T. Jacob: Unpublished research, 1975.

46. C. E. Wicks and F. E. Block: Thermodynamic Properties of 65 Elements-Their Oxides, Halides, Carbides and Nitrides, Bull. 605, Bureau of Mines, 1963 